\title{
Experimental Study of Drying Parameters of Ginger at Different Temperature and Moisture Content
}

\author{
Olusegun S. Olaoye, and A. J. Ogunleye
}

\begin{abstract}
Drying provides extended shelf life to agricultural crops in general and thus proper design of dryer will assist in drying them to acceptable level and quality. To design adequate dryer, necessary drying parameters of drying materials is necessary. This work involves experimental determination of effective drying parameters such as moisture content, moisture diffusion coefficient, density (true and bulk), specific heat, thermal conductivity and thermal diffusivity of ginger and to analyze these parameters in relation to each other. Fresh ginger rhizomes were washed to remove soil from the field, peeled and washed again in clean water and sliced into thin pieces. The sliced ginger was heat-treated by adding $200 \mathrm{ml}$ of clean water and steaming for 5-8 minutes in an aluminum pot, to a temperature of $85-90{ }^{\circ} \mathrm{C}$, and a light brown colour. Microwave oven, calorimeter, desiccators, thermometers, triple beams balance, micrometer screw gauge were used to determine the drying parameters of ginger. Effect of temperature and moisture content on some thermal properties was determined. The results of the experiments show that average initial moisture content for the ginger samples was $72.31 \%$, the true and bulk densities of the sample increased linearly from 0.5809 to $0.6338 \mathrm{~g} / \mathrm{cm}^{3}$ and 0.7405 to $0.7972 \mathrm{~g} / \mathrm{cm}^{3}$ respectively between the temperatures of $45-75$ ${ }^{\circ} \mathrm{C}$. The specific heat capacity of ginger varied from a minimum of $1.568 \mathrm{~kJ} \mathrm{~kg}^{-1} \mathrm{~K}^{-1}$ to a maximum of $2.026 \mathrm{~kJ} \mathrm{~kg}^{-1} \mathrm{~K}^{-1}$, with temperature in the range of $45^{\circ} \mathrm{C}$ to $75^{\circ} \mathrm{C}$ and moisture content in the range of 24.43 to $46.19 \%$ (d.b). The thermal conductivity of ginger samples varied from $0.316 \times 10^{-3}$ to $9.763 \times 10^{-4} \mathrm{Jm}^{-1} \mathrm{~S}^{-1}{ }^{\circ} \mathrm{C}$; as the moisture content and temperature increased. Thermal diffusivity of the ginger increased linearly from $3.149 \times 10^{-8}$ to $4.438 \times 10^{-8} \mathrm{~m}^{2} \mathrm{~s}^{-1}$ with increase in moisture content and temperature. Conclusively, the experimental study analysis show that specific heat of ginger varies with temperature. Also, there is variation in length, breath and thickness of ginger when subjected to temperature. Therefore, it can be said that ginger do shrinks when it is subjected to heat.
\end{abstract}

Index Terms-Dryer; Drying; Ginger; Moisture Content; Temperature; Thermal Conductivity.

\section{INTRODUCTION}

The ginger plant (Zingiber Officinale Roscoe) is a member of the Zingibereceae family. It is a perennial, slender plant that grows to a height of 2 to 3 feet, from underground rhizomes in tropical and subtropical climates of Asia, Africa, India, Jamaica, Mexico, China, Australia and Haiti. It has grass-like leaves that may grow up to a foot in length. The flowers are white or yellowish-green. Ginger grows well where the soil is not waterlogged and the annual rainfall exceeds $1500 \mathrm{~mm}$. It requires rich soils and both

Published on September 27, 2018

O. S. Olaoye, and A. J. Ogunleye are with Mechanical Engineering Department, Ladoke Akintola University of Technology,P.M.B. 4000, Ogbomoso, Nigeria (e-mail: osolaoye @ lautech.edu.ng). natural and artificial fertilizers may be added to obtain a good harvest. The rhizome that grows elongated underground is the useful part of the plant for human consumption. Ginger is used worldwide as a cooking Spice. It is an important spice used as a condiment in vegetable preparations. It is also an important ingredient in herbal medicines for the treatment of rheumatism, nervous diseases, gingivitis, toothache, asthma, stroke, constipation and diabetes [1]-[3]. The oil and oleoresins obtained from ginger are also used in many food items, soft drinks and beverages [4].

Fresh ginger is sold commercially without processing in the local market. Ginger that is freshly harvested has high moisture content of about $83 \%$ and this makes it susceptible to deterioration during transportation and therefore, there is need for a means of reducing the moisture contentment for its preservation [5]. Food preservation has been of tremendous help in agricultural industry because of its great importance in provision of food all year round, minimization of wastage and increase the income of the farmers. While it is undeniably important to increase yield of major food crop in many developing countries, an even greater increase in the amount of food available for human consumption could be realize by using appropriate food preservation method [6].

Drying is an operation in which a liquid, usually water, is removed from a wet solid in equipment termed dryers. The use of heat to remove liquids distinguishes drying from mechanical dewatering methods. Drying of foodstuffs is an important method of preservation and it is applicable to a wide range of industrial and agricultural product [7]. The reduced weight and bulk of dehydrated product and their dry shelf stability reduce products storage and distribution cost [8]. Drying is an energy intensive process which involves the removal of moisture from a crop until the moisture content of the crop is in equilibrium with the surrounding air. Crops are usually dried to a moisture content that will allow safe storage and/or further processing for example, milling. The drying behavior of different crops depends to a large extent on the physical characteristics of the crop, for example particle size, internal structure and composition.

Appropriate dryer design will assist in moisture reduction to a safe level and improve the quality of the dry products. Determination of physical and thermal properties of food crops is essential for appropriate dryer design. Thermophysical characteristics of fruits and vegetable tissues knowledge are very important for control and evaluation of the quality of foods during their storage and processing. Both theoretical and empirical relationship used when designing or operating heat processes require knowledge of the thermal properties of the food under consideration. Food 
thermal properties can be defined as those properties controlling the transfer of heat in a specified food. Heat transfer involves the transfer of heat into or out of a food. There are three ways that heat can be transferred: by radiation, conduction or convection. A better understanding of the way food materials respond to physical and chemical treatments allows for optimum design of food equipment and processes to insure food quality and safety. The main thermo-physical characteristics are thermal conductivity $\mathrm{K}$, thermal diffusivity $\mathrm{D}$ and apparent specific heat $\mathrm{C}$. These are interrelated [9].

Experimental study of drying parameter of various agricultural crops is widely used in agricultural engineering research. Several experiments have been proposed to describe the experimental study and parameters process involved in drying of agricultural product. Hence this project is to provide an experimental study of drying parameter of ginger.

\section{MATERIALS AND METHODS}

\section{A. Sample Preparation}

Fresh ginger (Zingiber officinale) was purchased at a local market in Ogbomoso, Nigeria. Ginger rhizomes were washed to remove soil from the field, peeled and washed again in clean water and sliced into thin pieces. Five hundred (500) grams of the sliced ginger was heat-treated by adding $200 \mathrm{ml}$ of clean water and steaming on the largest ring of a kitchen gas cooker for 5-8 minutes in an aluminum pot, to a temperature of $85-90{ }^{\circ} \mathrm{C}$, and a light brown colour. Two hundred and fifty (250) grams of the heat-treated ginger were dried in an oven (Carbolite 22265, Fison Way, Thetford U.K.), at $56-60^{\circ} \mathrm{C}$ for $24-26$ hours to a moisture content of $9.9-12.2 \%$. The moisture content was determined in triplicates using a moisture balance (Adam Equipment AMB 310, U.K). A few slices (16.7- 18.5g) of ginger were placed and spread evenly on the weighing pan of the balance, a drying temperature of $102^{\circ} \mathrm{C}$ was selected and the balance switched on. At steady conditions, the weight of the sample, drying time and moisture content in percentage were recorded. The other portion of $250 \mathrm{~g}$ of heat-treated ginger slices were dried in the sun, on a solar tent, for 2-3 days in the dry season or 3-5 days in the rainy season to similar moisture content level as obtained when dried in the oven (9.9-12.2\%). Two hundred and fifty (250) grams of raw sliced ginger were dried in the oven and another portion of 250 grams in the sun. The dried ginger was ground into powder using an electric kitchen blender (National MXT2GN, China) and sieved through a metallic sieve of calculated pore-size of $0.39 \mathrm{~mm}^{2}$. All equipment that came in contact with samples were steam sterilized or swabbed with $70 \%$ alcohol before use.

\section{B. Moisture Content Determination}

The moisture content of the samples was determined using AOAC [10] method. The sample was weighed into already weighed clean drying cans. The cans and the sample was placed in a well ventilated oven (Fisser Scientific Isotemp. oven, by Fisser Scientific Co. USA, Model 655F) maintained at $103{ }^{\circ} \mathrm{C}$ for 48 hours. This was repeated five times to obtain five different moisture contents (dry basis).
The percentage moisture content was calculated using the relation in reference [11]:

$$
\% \text { moisture cont. }(M C)=\frac{W^{1}-W^{2}}{S} \cdot 100
$$

where: $\mathrm{W}_{1}$ is weight of theempty can with the sample before drying $(\mathrm{g}), \mathrm{W}_{2}$ is weight of theempty can with the sample after drying $(\mathrm{g})$ and $\mathrm{S}$ is weight of the sample $(\mathrm{g})$

$$
\% \text { moisture cont. }\left(\text { d. } b=\frac{\text { Weight of water in product }}{\text { Weight of the dry matter of the sample }} \cdot 100(2)\right.
$$

\section{Bulk and True Density}

The bulk density of the selected samples was determined using the method described by [11] in which a $250 \mathrm{ml}$ volumetric cylinder was filled with samples of cut ginger and the weight of the samples was weighed. Bulk density was calculated using the ratio of the weight and the volume of the cylinder. Bulk density was calculated at each moisture level. True density is the ratio of the ginger sample mass to volume of compact powder without voids.

$$
\rho_{b}=\frac{\text { Weight of sample }}{\text { Volume of container }}
$$

where $\rho_{\mathrm{b}}$ is bulk density $\left(\mathrm{g} / \mathrm{cm}^{3}\right)$

\section{Thermal Diffusivity}

The thermal diffusivity of the selected samples was calculated using the experimental data of thermal conductivity, specific heat capacity and bulk densities of the samples [12].

$$
\propto=\frac{\mathrm{K}}{\rho_{\mathrm{b}} \mathrm{C}_{\mathrm{p}}}
$$

where $\alpha$ is thermal diffusivity $\left(\mathrm{m}^{2} \mathrm{~s}^{-1}\right), \mathrm{K}$ is thermal conductivity $\left(\mathrm{Jm}^{-1} \mathrm{~s}^{-1}{ }^{0} \mathrm{C}\right)$, and $\rho_{\mathrm{b}}$ is bulk density $\left(\mathrm{g} / \mathrm{cm}^{3}\right)$.

\section{E. Thermal Conductivity}

The thermal conductivity of the samples was determined using method of poor conductors as cited by [12]. In this method, a carbon steel of a known thickness and area was heated by steam from boiling water in a conical flask. The temperature of the carbon steel (hot) was measured until the temperature was constant $\left(\mathrm{T}_{1}\right)$. The temperature of the samples (cold), $T_{2}$ was measured and the sample was placed on the carbon steel while the thermometer was placed on the sample. The increase in temperature of the sample was recorded at two minutes interval for ten minutes. The slope of the graph of temperature against time was used to determine the thermal conductivity using the relation:

$$
\mathrm{K}_{\mathrm{S}}=\frac{\mathrm{XMC}}{\left(\mathrm{T}_{1}-\mathrm{T}_{2}\right) \mathrm{AS}}
$$

where $\mathrm{K}_{\mathrm{s}}$ is thermal conductivity of the sample $\left(\mathrm{Jm}^{-1} \mathrm{~s}^{-1}{ }^{0} \mathrm{C}\right)$, $\mathrm{X}$ is thickness of the sample (m), $\mathrm{M}$ is mass of sample $(\mathrm{g}), \mathrm{C}$ is specific heat capacity of sample $\left(\mathrm{Jg}^{-1}{ }^{0} \mathrm{c}^{-1}\right), \mathrm{Q}_{1}$ istemperature of carbon steel (hot) ${ }^{\circ} \mathrm{C}, \mathrm{Q}_{2}$ is temperature of sample (cold) ${ }^{\circ} \mathrm{C}, \mathrm{A}$ is area of carbon steel (equal to area of sample) $\left(\mathrm{m}^{2}\right), \mathrm{S}$ is slope of graph of temperature against time and $\mathrm{C}_{\mathrm{P}}$ is specific Heat Capacity $\left(\mathrm{Jg}^{-1} \mathrm{C}^{-1}\right)$. 


\section{F. Specific Heat Capacity}

The method of mixture as described by Anyakoha [13] was used to obtain the specific heat capacity of the selected samples. A sample of known mass, temperature and moisture content was dropped into the copper calorimeter of a known mass containing water of known mass and temperature. The mixture was gently stirred. At equilibrium, the final temperature of the mixture was noted and recorded. The experiments were performed at temperatures of 45, 55, 655,70 and $75^{\circ} \mathrm{C}$. The specific heat capacity was calculated at different moisture level using the equation [13].

$$
C_{s}=\frac{\operatorname{McCc}\left(\mathrm{T}_{\mathrm{f}}-\mathrm{T}_{1}\right)+\operatorname{MwCw}\left(\mathrm{T}_{\mathrm{f}}-\mathrm{T}_{1}\right)}{\operatorname{Ms}\left(\mathrm{T}_{2}-\mathrm{T}_{1}\right)}
$$

where $\mathrm{C}_{\mathrm{s}}, \mathrm{C}_{\mathrm{c}}$ and $\mathrm{C}_{\mathrm{w}}$ are the specific heats capacity of samples, calorimeter, and water respectively $\left(\mathrm{kJkg}^{-1} \mathrm{~K}^{-1}\right)$, $\mathrm{Mc}, \mathrm{Ms}$ and $\mathrm{Mw}$ is the masses of calorimeter, samples and water respectively $(\mathrm{kg}), \mathrm{T}_{1}$ is the initial temperature of water $(\mathrm{K})$ and $\mathrm{T}_{2}$ is the initial temperature of samples $(\mathrm{K})$.

\section{G. Volume and Density Determination}

The volume of Ginger of a known weight was determined by putting the sample in the cuboids of a known volume and the cuboids was filled with the sorghum grain. The ginger was removed while the volume occupied by the grains was measured in volumetric cylinder and the difference in the volume was calculated as a measure of the volume of the sample. The experiment was replicated three times and density was calculated using the ratio of the weight and the volume of the samples at different moisture level [11].

$$
\mathrm{V}_{\mathrm{s}}=\mathrm{V}_{\mathrm{c}}-\mathrm{V}_{\mathrm{g}}
$$

where $V_{s}$ is Volume of the sample $\left(\mathrm{cm}^{3}\right), V_{c}$ is Volume of cuboid $\left(\mathrm{cm}^{3}\right)$ and $\mathrm{V}_{\mathrm{g}}$ is Volume occupied by the grains $\left(\mathrm{cm}^{3}\right)$.

$$
\text { Density } \rho=\frac{M}{V}
$$

where $\rho$ is density $\left(\mathrm{g} / \mathrm{cm}^{3}\right), M$ is mass of the samples $(\mathrm{g})$ and $\mathrm{V}$ is volume of the samples $\left(\mathrm{cm}^{3}\right)$.

The volume used for the true density of the ginger was determined by multiplying the length, width and thickness of a slice, which equal the volume of the sample. The weight was divided by the volume of the sample which gave the true density of the sample at each moisture level.

\section{RESULTS AND DISCUSSION}

\section{A. Physical Properties}

\section{1) Moisture Content}

The average initial moisture content for the Ginger samples were $72.31 \%$ as shown in Table I.

TABLE I: OVERALL AVERAGE INITIAL MOISTURE CONTENT OF GINGER

\begin{tabular}{cc}
\hline \hline Sample label & Moisture Content (\%) \\
\hline A & 75.098 \\
B & 69.359 \\
C & 75.636 \\
D & 69.136 \\
Overall average & 72.31 \\
\hline \hline
\end{tabular}

\section{2) True and Bulk Densities of Ginger}

The true and bulk densities of the sample increased linearly from 0.5809 to $0.6338 \mathrm{~g} / \mathrm{cm}^{3}$ and 0.7405 to 0.7972 $\mathrm{g} / \mathrm{cm}^{3}$ respectively between the temperatures of $45-75^{\circ} \mathrm{C}$. Visranathan[14] reported similar increase with moisture content for linseed and Neemnut. The variations in true and bulk densities of ginger were best explained in Table II and Fig. 1 and 2.

TABLE II: RELATIONSHIP BETWEEN MOISTURE CONTENT TO TRUE DENSITY AND BULK DENSITY

\begin{tabular}{llll}
\hline & $\begin{array}{l}\text { MOISTURE } \\
\text { CONTENT }(\% \text { d.b })\end{array}$ & $\begin{array}{l}\text { TRUE DENSITY } \\
\left(\mathrm{g} / \mathrm{cm}^{3}\right)\end{array}$ & $\begin{array}{l}\text { BULK DENSITY } \\
\left(\mathrm{g} / \mathrm{cm}^{3}\right)\end{array}$ \\
\hline 1 & 24.43 & 0.5809 & 0.7405 \\
2 & 28.78 & 0.5902 & 0.7505 \\
3 & 37.49 & 0.6088 & 0.7704 \\
4 & 41.84 & 0.6181 & 0.7804 \\
5 & 46.19 & 0.6338 & 0.7972 \\
\hline
\end{tabular}

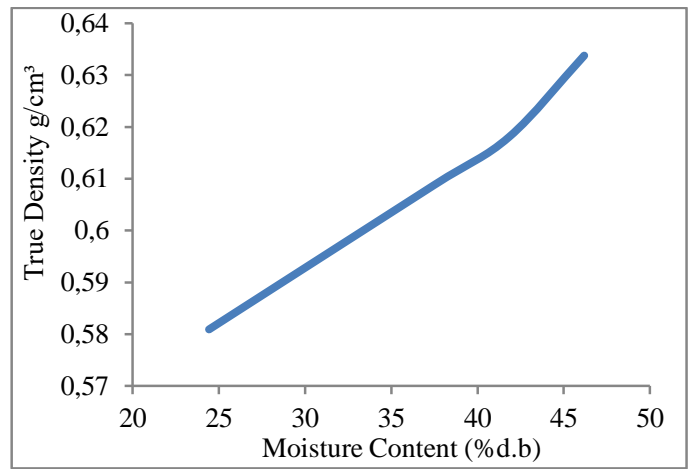

Fig. 1. Effect of moisture content on true density of Ginger

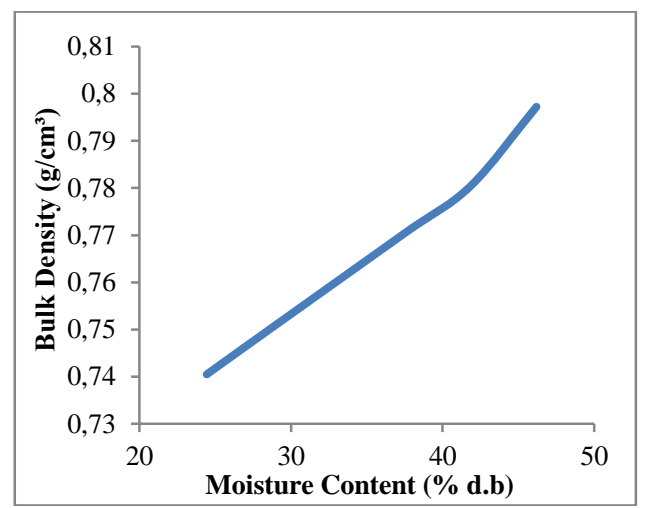

Fig. 2. Effect of moisture content on bulk density of Ginger

The values of sample densities were very low which indicate that the samples will be less dense in water. The variation in True and bulk densities with moisture content can be expressed mathematically using the following regression equations:

$$
\begin{array}{lc}
\rho=0.522+0.002 \mathrm{MC} & \mathrm{r}=0.995 \\
\rho_{\mathrm{b}}=0.678+0.002 \mathrm{MC} & \mathrm{r}=0.995
\end{array}
$$

where, $\rho$ is true density of Ginger sample $\left(\mathrm{g} / \mathrm{cm}^{3}\right), \rho_{\mathrm{b}}$ is bulk density $\left(\mathrm{g} / \mathrm{cm}^{3}\right)$, and $\mathrm{MC}=$ Moisture content $(\%, \mathrm{~d} . \mathrm{b})$.

\section{B. Thermal Properties \\ 1) Specific Heat Capacity}

The variations in specific heat capacity of ginger with moisture content and temperature were explained in Fig. 3 
and 4 respectively. The specific heat capacity of ginger varied from a minimum of $1.568 \mathrm{kJkg}^{-1} \mathrm{~K}^{-1}$ to a maximum of $2.026 \mathrm{~kJ} \mathrm{~kg}^{-1} \mathrm{~K}^{-1}$, with temperature in the range of $45^{\circ} \mathrm{C}$ to $75^{\circ} \mathrm{C}$ and moisture content in the range of 24.43 to $46.19 \%$ (d.b).

As depicted in Table III and Fig. 3 and 4, an increasing trend in the specific heat capacity of the two samples was observed with increase in both moisture content and temperature.

TABLE III: RELATIONSHIP BETWEEN SPECIFIC HEAT CAPACITY TO M.C AND TEMPERATURE

\begin{tabular}{llll}
\hline \hline & $\begin{array}{l}\text { SPECIFIC HEAT } \\
\text { CAPACITY } \\
\left(\mathrm{kJ} / \mathrm{kg} /{ }^{\circ} \mathrm{C}\right)\end{array}$ & $\begin{array}{l}\text { MOISTURE } \\
\text { CONTENT } \\
(\% \mathrm{~d} . \mathrm{b})\end{array}$ & $\begin{array}{l}\text { TEMPERATURE } \\
\left({ }^{\circ} \mathrm{C}\right)\end{array}$ \\
\hline 1 & 1.568 & 24.43 & 45 \\
2 & 1.649 & 28.78 & 55 \\
3 & 1.810 & 37.49 & 65 \\
4 & 1.890 & 41.84 & 70 \\
5 & 1.203 & 46.19 & 75 \\
\hline \hline
\end{tabular}

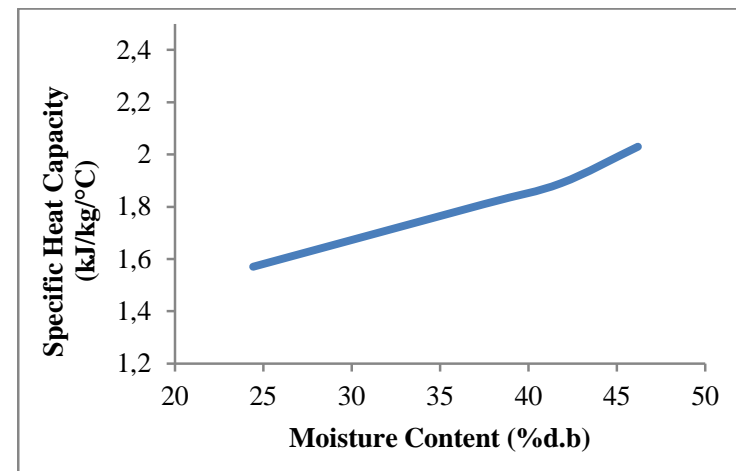

Fig.3. Effect of moisture content on specific heat capacity of Ginger

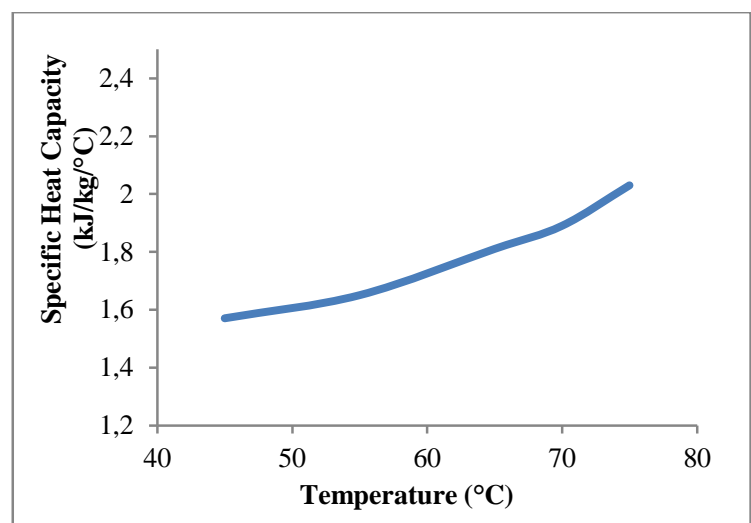

Fig. 4. Effect of temperature on specific heat capacity of Ginger

For Ginger:

$$
\begin{array}{lc}
\mathrm{Cp}=1.064+0.02 \mathrm{MC} & \mathrm{r}=0.993 \\
\mathrm{Cp}=0.86+0.015 \mathrm{~T} & \mathrm{r}=0.979
\end{array}
$$

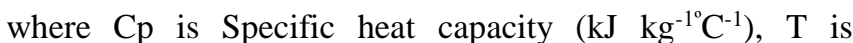
Temperature $\left({ }^{0} \mathrm{C}\right), \mathrm{r}$ is Correlation coefficient and $\mathrm{MC}$ is Moisture content $(\%$, d.b)

With the regression equations it was shown that there is a strong linear relationship between specific heat capacity, moisture content and temperature; and that, the specific heat capacity was dependent on moisture content and temperature of the samples.

The specific heat capacity of dairy cattle manure varied from 1.9925 to $3.606 \mathrm{~kJ} \mathrm{~kg}^{-1} \mathrm{~K}^{-1}$ at the temperature range of 40 to $60^{\circ} \mathrm{C}$ and moisture content ranged from 20 to $82 \%$ (w.b), respectively [15]. Tansakul and Lumyong [16] research revealed that the specific heat capacity of mushroom varied from 2.284 to $4.008 \mathrm{~kJ} \mathrm{~kg}^{-1} \mathrm{~K}^{-1}$ at temperature range of 30 to $80{ }^{\circ} \mathrm{C}$ and moisture content range of 30 to $90 \%$ (w.b) respectively.

\section{2) Thermal Conductivity}

The thermal conductivity of ginger samples varied from $0.316 \times 10^{-3}$ to $9.763 \times 10^{-4} \mathrm{Jm}^{-1} \mathrm{~S}^{-1}{ }^{\circ} \mathrm{C}$; as the moisture content and temperature increased. Similar trend was observed in the investigations of Oluka and Bardey [12] in which the thermal conductivity of pigeon pea flour paste varied from 0.566 to $0.800 \mathrm{Jm}^{-1} \mathrm{~S}^{-1}{ }^{\circ} \mathrm{C}$. Aviara and Haque [17] investigation showed that the thermal conductivity of whole and ground seed kernel of guna seed increased from 0.0711 to 0.1282 and from 0.087 to $0.1260 \mathrm{Wm}^{-1} \mathrm{~S}^{-1}$, as the moisture content and temperature increase.

The changes in the thermal conductivity of the ginger with moisture content at different temperatures are presented in Table IV and Fig. 5 and 6; it was shown that the thermal conductivities increased with increasing moisture content and temperature.

TABLE IV: RELATIONSHIP BETWEEN THERMAL CONDUCTIVITY, MOISTURE

\begin{tabular}{llll}
\multicolumn{3}{c}{ CONTENT AND TEMPERATURE } \\
\hline \hline & THERMAL & MOISTURE & TEMPERATURE \\
& CONDUCTIVITY & $\begin{array}{l}\text { CONTENT } \\
(\% \mathrm{~d} . \mathrm{b})\end{array}$ & $\left({ }^{\circ} \mathrm{C}\right)$ \\
& $\left(\mathrm{J} / \mathrm{m} / \mathrm{s}^{\circ} \mathrm{C}\right) \times 10^{-3}$ & 24.43 & 45 \\
\hline 1 & 0.316 & 28.78 & 55 \\
2 & 0.432 & 37.49 & 65 \\
3 & 0.664 & 41.84 & 70 \\
4 & 0.780 & 46.19 & 75 \\
5 & 0.976 & \\
\hline \hline
\end{tabular}

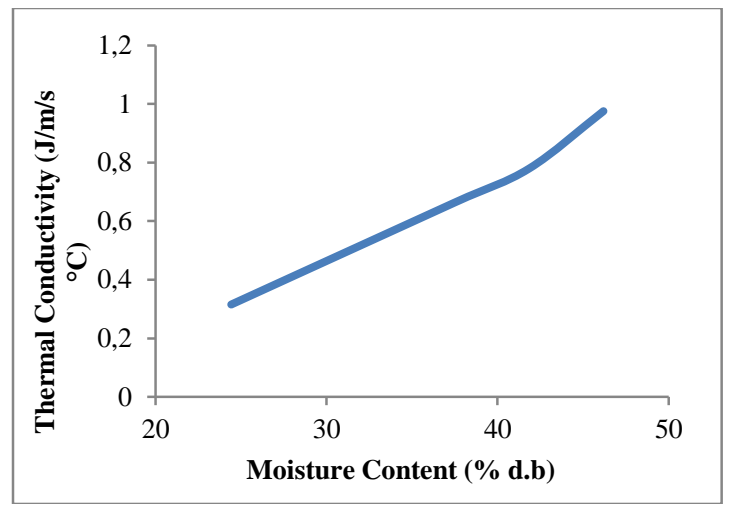

Fig. 5. Effect of moisture content on thermal conductivity of Ginger

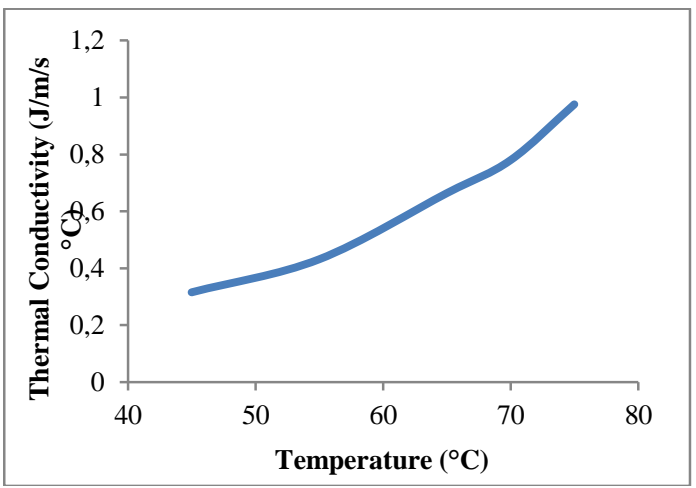

Fig. 6. Effect of temperature on thermal conductivity of Ginger

The relationship existing between thermal conductivity of the two residues with moisture content and temperature can be expressed mathematically using the following regression 
equations:

$$
\begin{array}{lc}
\text { For Ginger: } & \\
\mathrm{K}=0.410+0.029 \mathrm{MC} & \mathrm{r}=0.994 \\
\mathrm{~K}=0.705+0.021 \mathrm{~T} & \mathrm{r}=0.980
\end{array}
$$

Where is $\mathrm{Cp}$ is Specific heat capacity $\left(\mathrm{kJ} \mathrm{kg}^{-{ }^{\circ}} \mathrm{C}^{-1}\right)$, $\mathrm{T}$ is Temperature $\left({ }^{0} \mathrm{C}\right), \mathrm{r}$ is Correlation coefficient and $\mathrm{MC}$ is Moisture content (\%, d.b).

The simple regression analysis showed that there is a linear relationship between thermal conductivity, temperature and moisture content of the ginger and that the thermal conductivity was dependent on moisture content and temperature.

\section{3) Thermal Diffusivity}

The change of thermal diffusivity of ginger with moisture content and temperature presented in Table V and Fig. 7 and 8; shows that the thermal diffusivity of the ginger increased linearly from $3.149 \times 10^{-8}$ to $4.438 \times 10^{-8} \mathrm{~m}^{2} \mathrm{~s}^{-1}$ for ginger with increase in moisture content and temperature. Similar trend was reported for the thermal diffusivity of borage seeds in [18].

TABLE V: RELATIONSHIP BETWEEN THERMAL DIFFUSIVITY TO M.C

\begin{tabular}{llll}
\multicolumn{3}{c}{ AND TEMPERATURE } \\
\hline \hline & $\begin{array}{l}\text { THERMAL } \\
\text { DIFFUSIVITY } \\
\left(\mathrm{m}^{2} / \mathrm{s}\right) \times \mathbf{1 0}^{-\mathbf{8}}\end{array}$ & $\begin{array}{l}\text { MOISTURE } \\
\text { CONTENT } \\
(\% \mathrm{~d} . \mathrm{b})\end{array}$ & $\begin{array}{c}\text { TEMPERATURE } \\
\left({ }^{\circ} \mathrm{C}\right)\end{array}$ \\
\hline 1 & 3.149 & 24.43 & 45 \\
2 & 3.376 & 28.78 & 55 \\
3 & 3.829 & 37.49 & 65 \\
4 & 4.055 & 41.84 & 70 \\
5 & 4.438 & 46.19 & 75 \\
\hline \hline
\end{tabular}

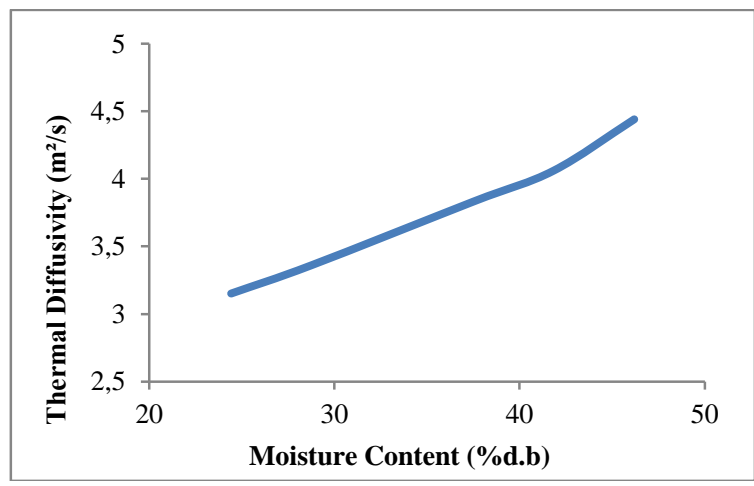

Fig. 7. Effect of thermal diffusivity on moisture content of Ginger

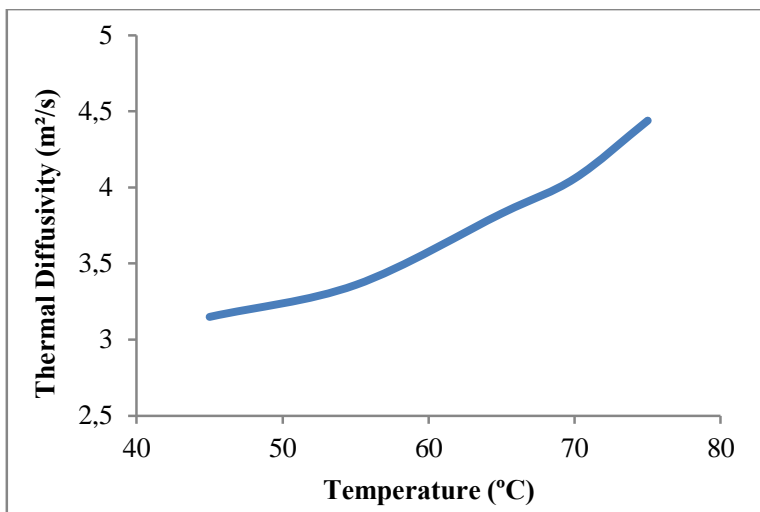

Fig. 8. Effect of temperature on thermal diffusivity of Ginger

The relationship existing between thermal diffusivity of the two residues with moisture content and temperature can be expressed mathematically using the following regression equations:

$$
\begin{array}{lc}
\text { For ginger: } & \\
\alpha=1.711+0.057 \mathrm{MC} & r=0.994 \\
\alpha=1.155+0.642 \mathrm{~T} & \mathrm{r}=0.980
\end{array}
$$

where $\alpha$ is Thermal diffusivity $\left(\mathrm{m}^{2} \mathrm{~s}^{-1}\right)$, $\mathrm{T}$ is Temperature $\left({ }^{0} \mathrm{C}\right)$, $\mathrm{r}$ is Correlation coefficient and $\mathrm{MC}$ is Moisture content $(\%, \mathrm{~d} . \mathrm{b})$

The regression equations showed that there is a linear relationship between thermal diffusivity, temperature and moisture content of the ginger.

Determination of Shrinkage

Sample A -Weight of can $=19.47$

Sample B - weight of can $=19.45$

TABLE VI: RESULT OF INITIAL VALUE (WEIGHT, LENGTH, BREADTH AND THICKNESS)

\begin{tabular}{lll}
\hline \hline & Sample A & Sample B \\
\hline Initial Weight $\left(\mathrm{W}_{\mathrm{o}}\right)(\mathrm{g})$ & 33.10 & 27.13 \\
Initial Length $\left(\mathrm{L}_{\mathrm{o}}\right)(\mathrm{mm})$ & 53.00 & 32.00 \\
Initial Breadth $\left(\mathrm{B}_{\mathrm{o}}\right)(\mathrm{mm})$ & 30.25 & 12.15 \\
Initial Thickness $\left(\mathrm{T}_{\mathrm{o}}\right)(\mathrm{mm})$ & 13.16 & 16.17 \\
\hline \hline
\end{tabular}

\begin{tabular}{|c|c|c|c|c|c|c|c|c|c|c|c|c|}
\hline & \multicolumn{4}{|c|}{$D_{b}$ after 1 hour } & \multicolumn{4}{|c|}{$D_{b}$ after 2 hours } & \multicolumn{4}{|c|}{$D_{b}$ after 3 hours } \\
\hline & $\overline{W 1}$ & $\mathrm{L1}$ & $\mathrm{B} 1$ & $\mathrm{~T} 1$ & $\mathrm{~W} 2$ & $\mathrm{~L} 2$ & $\mathrm{~B} 2$ & $\mathrm{~T} 2$ & W3 & L3 & B3 & T3 \\
\hline Sample A & 30.89 & 5200 & 25.23 & 12.14 & 28.42 & 50.5 & 25.21 & 11.13 & 28.30 & 50.00 & 25.10 & 11.08 \\
\hline Sample B & 25.39 & 31.00 & 10.13 & 15.16 & 23.86 & 30.00 & 9.11 & 15.13 & 23.52 & 30.00 & 9.06 & 15.10 \\
\hline
\end{tabular}

There is variation in $1, b, t$, of gingers when subjected to heat, therefore, it can be said that ginger do shrinks when subject to heat. This is necessary when designing and modelling the drying process of ginger.

TABLE VII: RESULT OF WEIGHT, LENGTH, BREATH AND THICKNESS AFTER THREE HOURS

\section{CONCLUSIONS}

An evaluation has been carried out on determination of physical and thermal properties of ginger. The varied moisture contents for the samples were varied between 24.43 to $46.19 \%$ (d.b) of temperature between 45 to $75^{\circ} \mathrm{C}$ respectively.

It was observed that the true and bulk densities for the ginger were dependent on moisture content. An increase in the moisture content led to increase in true and bulk densities of the samples. This shows that there is a positive correlation between density (true and bulk) and moisture content of the samples. Also, the values obtained for the bulk densities of the ginger were greater than their true densities which imply that more of this sample can be transported in bulk or packed when they are to be consumed or used for manufacturing purposes.

The thermal properties of ginger samples were strongly 
dependent on moisture content and temperature. The specific heat capacity of the ginger increased with both moisture content and temperature between $1.568 \mathrm{kJkg}^{-1} \mathrm{~K}^{-1}$ to $2.026 \mathrm{~kJ} \mathrm{~kg}^{-1} \mathrm{~K}^{-1}$.

The value of the thermal conductivity lies between $0.316 \times 10^{-3}$ to $9.763 \times 10^{-4} \mathrm{Jm}^{-1} \mathrm{~S}^{-1}{ }^{\circ} \mathrm{C}$ for ginger between the temperature range of $45-75{ }^{\circ} \mathrm{C}$. The values obtained for the thermal conductivity of the sample were very low which indicates that the samples were poor heat conductors.

An increasing trend in the thermal diffusivity of the sample were observed with increase from $3.149 \times 10^{-8}$ to $4.438 \times 10^{-8} \mathrm{~m}^{2} \mathrm{~s}^{-1}$ between the temperature of $45-75^{\circ} \mathrm{C}$ which implies that there is a linear relationship between temperature, moisture content and thermal diffusivity of the sample. The simple regression equations show that there is a positive correlation between thermal properties of the sample and moisture content and temperature.

\section{REFERENCES}

[1] Awang, D.V.C. "Ginger". Can. Pharm. Journal., vol. 125, pp 309311, 1992.

[2] Wang, Z., Sun, J., Liao, X., Chen, F., Zhao, G., and Wu, J. "Mathematical modeling on hot air drying of thin layer apple pomace". Journal of Food Engineering, vol.40, pp. 39-46, 2007.

[3] Tapsell, T. W., Aristee, G., Donko, P and Wunbeldow, L. Hand Book of Shea Processing Using a Manually Operated Bridge Press. A publication of National Resources Institute of Chathman, England.1997.

[4] Singh, L. A. O., Aviara, V. A and Aregbesola O. A."Some Engineering Properties of Locust Bean Seed". Journal of Food Engineering. vol. 55, pp.95-99, 2002.

[5] Afolabi, T.J, Tunde-Akintunde, T. Y. and Oyelade, O.J. "Influence of Drying Conditions on the Effective Moisture Diffusivity and Energy
Requirements of Ginger Slices". Jouurnal of Food Research, vol. 3(5): pp $103-112,2014$.

[6] Bardey, N. N."Thermal Properties of Food Agricultural Materials". Gordon and Breach Press. New York. USA, 1980

[7] Aroldo, A., Fernanda, E. X. M., Abraham D. G. and Zilda D. S. A. "Vacuum Drying of Carrot (Daucus carota): Effects of Pretreatments and Parameters Process". Proceedings of the 14th International Drying Symposium (IDS 2004) São Paulo, Brazil, C: pp.2021-2026, 2004.

[8] Doymaz, I. "Drying Behavior of Green Beans". Journal of Food Engineering. vol. 69, pp 161-165, 2005.

[9] Aviara, N. A. and Haque, M. A. "Moisture Dependence of Thermal Properties of Sheanut Kernel". Journal of food Engineering, vol.47, pp. 109-113, 2001.

[10] A.O.A.C. (Association of Official Analytical Chemists). Official Methods of Analysis,15th edn. (Gaithersburg, S. edn). AOAC Press, Washington DC., USA. pp. 78- 90, 1999.

[11] Singh, K. K and Goswami, T. K. "Physical Properties of Cumin Seed". Journal of Agricultural Engineering Research, vol. 64, pp. 9398, 1996.

[12] Oluka, S. I., and Bardey, I. A. "Thermal Properties of Pigeon Pea. Journal of Agric". Engrineering and Technology.vol. 8, pp.372-379, 2000.

[13] Anyakoha, T. "Heat Transfer Through Materials". Africana first Publisher Onitsha. Pp.63-80. Third edition. (2007).

[14] Visvanathan, R., Palanisamy, P.T., Gothandapani, L.and Sreenarayanan, V.V. "Physical properties of neem nut". Journal of Agricultural Engineering Research, vol. 63(1), pp.19-25, 1996.

[15] Nayyeri, M.A., Kianmehr, M.H. Arabhosseini, A. and Hassan-Beygi, S.R. "Thermal properties of dairy cattle manure institute of Agrophysics", Polish Academy of Sciences, vol.23, pp. 359-366, (2009).

[16] Tansakul A. and Lumyong R.."Thermal properties of straw mushroom". Journal of Food Engineering, vol. 87, pp. 91-98, 2008.

[17] Aviara, N. A and Haque, M. A. "Moisture Dependence of Thermal Properties of Sheanut Kernel". Journal of food Engineering, vol. 47, pp. 109-113, 2001

[18] Yang, W., Sokahansaj, S., Tang, J. and Winter P."Determination of Thermal Conductivity, Specific heat Capacity and Thermal diffusivity of borage seeds". Biosystem Engineering,vol. 82 (2), pp. 169-176, 2002 . 